\title{
COMPARING THE EFFECT OF STATIC AND PNF STRETCHING ON HIP JOINT FLEXIBLLITY OF UN-TRAIIIIMG FEMALE STUDENTS
}

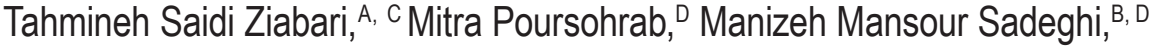 \\ Delaram Sorahi, ${ }^{B}, D^{B}$ Behnaz Motekalemi ${ }^{B}$
}

\author{
Faculty of Physical Education and Sport Sciences, University of Guilan, Rasht, Iran \\ A Study Design; ${ }^{\mathrm{B}}$ Data Collection; ${ }^{\mathrm{C}}$ Statistical Analysis; ${ }^{\mathrm{D}}$ Manuscript Preparation \\ Address for corpespondence: \\ Mitra Poursohrab \\ University of Guilan, Faculty of Physical Education and Sport Sciences, Department of Physician Science, Rasht, Iran \\ E-mail: Bmp1373@gmail.com
}

\begin{abstract}
Ahstract. Since many of people in their functional activities mostly place their knee joint in flexed position, the hamstring muscles tend to be shortened. On the other hand, shortness of these muscles affect the knee joint directly and the Hip Joint Flexibility indirectly. The purpose of this study is to compare the effect of static and PNF stretching on hip joint flexibility of un-training female students. Twenty-four 18-30 years old un-training female students without any history of pathology in hip, knee or back were selected. They were divided into three groups with 8 women in each group (static stretch, PNF stretch and control). The two stretch groups received stretching program three days every week for six weeks, while the control group did not. The result shows that range of hip joint flexibility of both groups of static and PNF stretching increased $(P<0.05)$. However, there was no significant difference between these two groups $(P>0.05)$. The while it remained unchanged in control subjects $(P>0.05)$. Employing both methods (static and PNF stretching) increase the hip joint flexibility. The findings of this study suggest that optimal flexibility is achieved with a combination of these two methods. Thus, we recommend the combined training method to athletes who require very high flexibility.
\end{abstract}

Key WOrdl: hip joint flexibility, static stretching, PNF stretching, student

\section{Introduction}

Flexibility is a very important duty and performance of human in order to achieve successfully his/her skills and abilities in a wide range of conditions. The high level of flexibility, adaptability not only introduces a factor in preventing injury but also causes a rapid movement to be performed easily and without any pressures. Thus, increasing flexibility is not only to meet the demands and needs of sport skills but it must be somewhat beyond the scope and the extent of the required maximum exercise (ability to create and develop flexibility storage) should be strengthened. The lack of flexibility may lead to failure and susceptibility to various disorders. Muscular flexibility is a major component of physical fitness and has long been the center of attention for athletes, champions, physical trainers, physiotherapists and rehabilitation professionals (Song, Seo, Shin, 2015). The results of this study show 
that the primary goal of flexibility is to increase the capacity of muscle fibers capable the elastic or stretching properties. The lack of sufficient activity to stimulate and maintain the readiness of the anti-gravity muscles and the use of muscles tensions doing the exercises of flexibility is necessary for some parts of the body; these parts include thigh, front hip, back, neck and chest (Blackhurst, Peterson, Herzog, Zimmerman, 2015; Song et al., 2015).

Stretching ligaments and muscles improve the range of motion in major joints of the body and the optimal muscle performance is the initial tension (McHugh Cosgrave, 2010)

The application of stretching exercise for improving flexibility is based on the notion that such exercise may reduce the occurrence, intensity and duration of muscular-ligamentous and articular injuries (Behm, Blazevich, Kay, McHugh, 2016).

Muscle flexibility is enhanced through various stretching exercises, including static, ballistic, proprioceptive neuromuscular facilitation (PNF) and vibration training. One example of PNF training is contraction-rest which some sources report to be superior to static stretching (Meliggas, Papadopoulos, Gissis, Zakas, Brabas, 2015). Another study, however, reported that 4 weeks of static stretching yielded better results compared to PNF (McGowan, Pyne, Thompson, Rattray, 2015). Some researchers have noted that vibration stretching methods are more efficacious for improving muscle flexibility (McGowan et al., 2015; Wagner et al., 2010). Funk, Swank, Mikla, Fagan, Farr (2003) compared the PNF stretching and static exercises on the hamstring flexibility. The results showed that PNF exercises made the maximum development of motion range in this regard (Funk, Swank, Mikla, Fagan, Farr, 2003). Jordan, Korgaokar, Farley, Caputo (2012) studied the long term effects of two types of PNF and static stretching on jumping performance and the range of motion. The results showed that stretching exercises caused an increase to the range of motion in both groups and also they did not affect the jumping scores (Jordan, Korgaokar, Farley, Caputo, 2012). The results of many studies have confirmed that static stretching methods and PNF muscular nerve facilitation had effect on the flexibility of hamstring muscles of non-dominant leg (knee active range of motion opening), but statistically there was no significant difference between the effect of static stretching and PNF methods on the flexibility of hamstring muscles of non- dominant leg (Jordan et al., 2012; Zarghami, Moghaddam, Hojjat, 2012).

Considering all these reports, there is no consensus regarding the optimal stretching exercise. Moreover, most studies have dealt with the mechanism of one or more stretching methods and have rarely considered the impact of comparing the effect of static and PNF stretching on hip joint flexibility. Thus, it is still uncertain which method will yield the optimal hip joint flexibility. The present study aims at comparing the effect of static and PNF stretching on hip joint flexibility of un-training female students.

\section{Methods}

\section{Suljects}

Twenty-four 18-30 years old un-training female through simple random sampling, were classified into 3 groups: static stretch $(n=8)$, PNF stretch $(n=8)$ and control $(n=8)$ groups. The subjects were female college students aged 18-30 years, and exercised at the Guilan University fitness center in Iran. All the subjects submitted a written consent form, and all the study procedures were approved by the Human Care and Use Committee of the Society of Sport Research Institute at Guilan University. 


\section{Experimental procedures}

The two stretch groups received stretching program three days every week for six weeks, while the control group was not. The program was composed of 3 steps: warm-up, static stretch or PNF stretch and cool down. In the PNF group, the training consisted of 3 bouts of stretching per week: in each bout, the participant would rest the heel of her foot on a platform with his knee fully extended and then pushed the heel downwards isometrically to contract the posterior thigh muscles for 5 seconds. Then she would flex the waist to stretch the hamstring muscles for 30 seconds. In each bout, this exercise would be repeated three times for each leg (Zarghami et al., 2012).

\section{Static Passive Hamstring Flexibility test}

This test was performed in the supine position on an exercise bench. The functional knee brace was worn for testing. Passive stretching utilizes an external agent to assist with the stretch. The participant used a Velcro strap around the ankle to assist with pulling the limb into hip flexion. The dominant leg was flexed to the terminal ROM or until a mild discomfort/tightness was felt in the back of thigh (Meliggas et al., 2015). This position was maintained for five seconds following which the limb was slowly lowered to the resting position.

\section{Statistical analyses}

Descriptive statistics of range mean and standard deviation were computed on all the data. One-way ANOVA was calculated across all the groups over the 6 weeks of the study. A paired t-test was computed to compare the post intervention and carry over values. Level of significance was set at 0.05 Alphas.

\section{Results}

The subjects' characteristics did not significantly differ between the groups $(P>0.05)$ (Table 1). Figure 1 depicts the flexibility of the three static, PNF and control groups on pretest and posttest. As the figure illustrates, one-way analysis of variance indicated a significant difference between the three groups $(P=0.001)$. The results of post-hoc LSD test showed that this difference results from the difference between the PNF with control groups $(P=0.001)$, as well as between the static and control groups $(P=0.004)$; while it remained unchanged in control subjects $(P>0.05)$.

Table 1. Characteristics of the subjects (Mean \pm SD)

\begin{tabular}{lcccc}
\hline \multicolumn{1}{c}{ Variables } & Static Group & PNF Group & Control Group & P \\
\hline Age, years & $20.16 \pm 2.91$ & $21.13 \pm 1.72$ & $21.96 \pm 3.21$ & 0.598 \\
Height, $\mathrm{cm}$ & $162.13 \pm 5.41$ & $163.34 \pm 3.45$ & $161.9 \pm 2.41$ & 0.673 \\
Weight, $\mathrm{kg}$ & $60.21 \pm 6.60$ & $59.29 \pm 4.60$ & $57.33 \pm 7.19$ & 0.389 \\
\hline
\end{tabular}




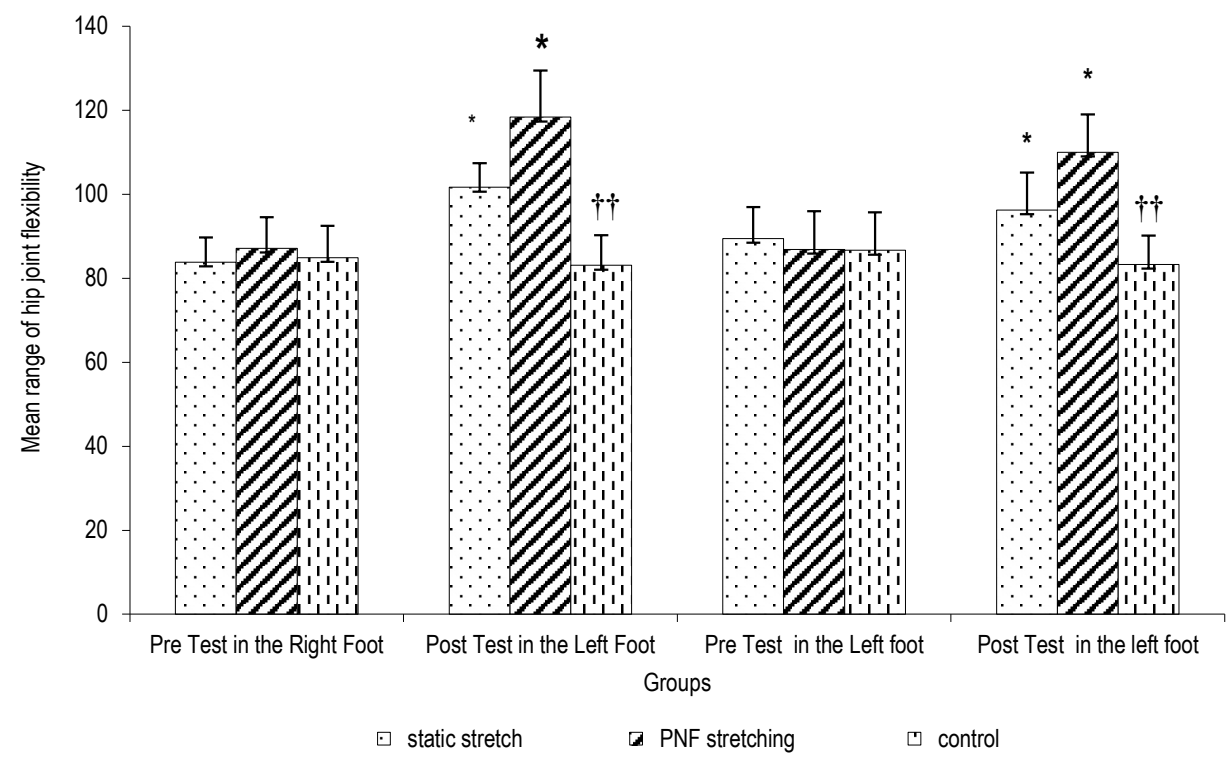

* - significant difference between pretest and posttest; $\uparrow \dagger$ - significant difference from the combined group on posttest.

Figure 1. Flexibility of participants in the 3 groups on pretest and posttest

\section{Discussion}

Flexibility is an important physiological component of physical fitness, and reduced flexibility can cause inefficiency in the workplace and is also a risk factor for low back pain. This study focused on comparing the effect of static and PNF stretching on hip joint flexibility of un-training female students. The results of the study indicated that a period of 6 weeks of PNF and stretching exercises significantly increased the range of hip flexibility this way, thus, this method is considered as a desirable way to improve flexibility and muscle strength as well. On the other hand, this increase can be due to the rapid effect of muscular nervous mechanisms in deep- sense pathways of isometric stretching contractions.

Yuktasir, Kaya (2009) stated that in spite of increasing motion range followed by PNF methods, the activity of Electromyography in muscles is greater than static stretching method (Yuktasir Kaya, 2009). Blackhurst et al. (2015) reported that the static stretching of motion range is being double increases then dynamic stretching. Thus, due to a little discomfort of muscles with static stretching method, the tendency is high for applying the method preferably (Blackhurst et al., 2015). Lima et al. (2014) believe that the cause of most dynamic techniques effects is the increase of metabolite processes in which increases the temperature and decreases the muscle viscosity allowing the muscle slowly gets contracted. The warmed-up muscle is being arranged easily with the forces increasing the flexibility (Lima et al., 2014). Fasen et al. (2009) investigated the impact of 8 weeks of training with PNF, active and passive stretching to report that PNF and active stretching yield better knee range of motion while passive stretching yields better hamstring flexibility (Fasen et al., 2009). The impact of PNF and static stretching on muscle flexibility is mediated via neurophysiologic mechanisms, including the muscle stretch reflex (Miyahara, 
Naito, Ogura, Katamoto, Aoki, 2013; Place, Blum, Armand, Maffiuletti, Behm, 2013). These mechanisms increase the level of stretch endurance alongside improved muscle power and reduced pain sensation. Studies indicate that training aimed at improving neuromuscular control; including PNF and static training expedite flexibility and are more appropriate for treatment and rehabilitation of pelvic injuries compared to other stretching exercises (Place et al., 2013; Wicke, Gainey, Figueroa, 2014).

Other factors such as period of stretching, frequency of stretching and the age of people under study play key role in obtaining different results (Miyahara et al., 2013; Zarghami et al., 2012). According to the results of the researches and to prevent the effect of these intervening variables, all indices were equally selected for both groups.

In conclusion, although our findings confirm the positive impact of proprioceptive neuromuscular facilitation and static exercises alone on Hip Joint Flexibility, we recommend athletes (particularly those who require an excellent level of flexibility such as gymnasts, ballerinas, divers and wrestlers) to combine both exercises (PNF and static training) in order to achieve level of muscle relaxation and flexibility necessary for the complicated motions of their field.

\section{Acknowledgments}

The authors gratefully acknowledge all the subjects who took part in this study for their cooperation. The authors also acknowledge the financial support of the Department of Physical Education and Sport Science, University of Guilan, Iran.

\section{Referencess}

Behm, D.G., Blazevich, A.J., Kay, A.D., McHugh, M. (2016). Acute effects of muscle stretching on physical performance, range of motion, and injury incidence in healthy active individuals: a systematic review. Applied Physiology, Nutrition, and Metabolism, 41 (999), 1-11.

Blackhurst, N.R., Peterson, J.C., Herzog, V.W., Zimmerman, E.P. (2015). A Comparison of Static Stretching Versus Combined Static and Ballistic Stretching in Active Knee Range of Motion. Internet Journal of Allied Health Sciences and Practice, 13 (4), 11.

Fasen, J.M., O'Connor, A.M., Schwartz, S.L., Watson, J.O., Plastaras, C.T., Garvan, C.W., ... Akuthota, V. (2009). A randomized controlled trial of hamstring stretching: comparison of four techniques. The Journal of Strength Conditioning Research, 23 (2), $660-667$.

Funk, D.C., Swank, A.M., Mikla, B.M., Fagan, T.A., Farr, B.K. (2003). Impact of prior exercise on hamstring flexibility: a comparison of proprioceptive neuromuscular facilitation and static stretching. The Journal of Strength Conditioning Research, 17 (3), 489-492.

Jordan, J.B., Korgaokar, A.D., Farley, R.S., Caputo, J.L. (2012). Acute effects of static and proprioceptive neuromuscular facilitation stretching on agility performance in elite youth soccer players. International Journal of Exercise Science, 5 (2), 2.

Lima, B.N., Lucareli, P.R., Gomes, W.A., Silva, J.J., Bley, A.S., Hartigan, E.H., Marchetti, P.H. (2014). The acute effects of unilateral ankle plantar flexors static-stretching on postural sway and gastrocnemius muscle activity during single-leg balance tasks. Journal of sports science medicine, 13 (3), 564.

McGowan, C.J., Pyne, D.B., Thompson, K.G., Rattray, B. (2015). Warm-Up Strategies for Sport and Exercise: Mechanisms and Applications. Sports Medicine, 45 (11), 1523-1546.

McHugh, M.P., Cosgrave, C. (2010). To stretch or not to stretch: the role of stretching in injury prevention and performance. Scandinavian journal of medicine science in sports, 20 (2), 169-181.

Meliggas, K., Papadopoulos, C., Gissis, I., Zakas, A., Brabas, I.S. (2015). Effects of a Static and Dynamic Stretching Program on Flexibility, Strength, and Speed of School-Age Children. International Journal of Applied, 5 (3).

Miyahara, Y., Naito, H., Ogura, Y., Katamoto, S., Aoki, J. (2013). Effects of proprioceptive neuromuscular facilitation stretching and static stretching on maximal voluntary contraction. The Journal of Strength Conditioning Research, 27 (1), 195-201. 
Place, N., Blum, Y., Armand, S., Maffiuletti, N.A., Behm, D.G. (2013). Effects of a short proprioceptive neuromuscular facilitation stretching bout on quadriceps neuromuscular function, flexibility, and vertical jump performance. The Journal of Strength Conditioning Research, 27 (2), 463-470.

Song, W.-M., Seo, H.-J., Shin, W.-S. (2015). Effects of Electric Stimulation with Static Stretching on Hamstrings Flexibility. The Journal of Korean Physical Therapy, 27 (3), 164-168.

Wagner, T., Behnia, N., Ancheta, W.-K.L., Shen, R., Farrokhi, S., Powers, C.M. (2010). Strengthening and neuromuscular reeducation of the gluteus maximus in a triathlete with exercise-associated cramping of the hamstrings. journal of orthopaedic sports physical therapy, 40 (2), 112-119.

Wicke, J., Gainey, K., Figueroa, M. (2014). A comparison of self-administered proprioceptive neuromuscular facilitation to static stretching on range of motion and flexibility. The Journal of Strength Conditioning Research, 28 (1), 168-172.

Yuktasir, B., Kaya, F. (2009). Investigation into the long-term effects of static and PNF stretching exercises on range of motion and jump performance. Journal of bodywork and movement therapies, 13 (1), 11-21.

Zarghami, F., Moghaddam, J.B., Hojjat, S. (2012). Effect of PNF exercises on the range of hip flexion motion of non-athletes women. European Journal of Experimental Biology, 2 (4), 1235-1239.

Cite this article aS: Ziabari, T.S., Poursohrab, M., Sadeghi, M.M., Sorahi, D., Motekalemi, B. (2016). Comparing the Effect of Static and PNF Stretching on Hip Joint Flexibility of Un-training Female Students. Central European Journal of Sport Sciences and Medicine, 14 (2), 73-78. DOI: 10.18276/cej.2016.2-08. 